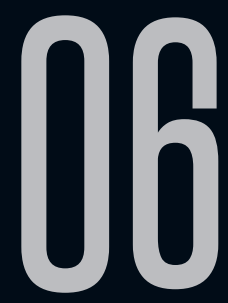

\title{
O DUPLO COMO O CRIMINOSO: UMA ANÁLISE DO LIVRO A METADE SOMBRIA, DE STEPHEN KING
}

Maristela Scheuer Deves (PUC-RS)

Recebido em 15 mar 2020. Maristela Scheuer Deves é Mestranda em Letras Aprovado em 22 jun 2020. - Escrita Criativa pela PUCRS e bolsista do CNPq. Dedica-se ao estudo e à escrita de literatura infantil e infanto-juvenil, sendo autora de seis livros de ficção para esse público, entre eles $O$ Baú dos Contos de Fadas (2019), O Sumiço das Bergamotas (2018) e Uma Cidade Desassombrada (2014). Participa do grupo de pesquisas "O fantástico em tradução: textos teóricos fundamentais" e do grupo de estudos "Cartografias narrativas em língua portuguesa: redes e enredos de subjetividade II".

Lattes: http://lattes.cnpq.br/6814850772624785

Página pessoal: facebook.com/escritoramaristela

E-mail: maristela.deves@edu.pucrs.br

ORCID iD: https://orcid.org/0000-0002-5410-0192

Resumo: Desde a antiguidade, a figura do duplo marca presença no imaginário humano, nas suas mais variadas formas e denominações - sombra, reflexo, sósia, irmão gêmeo, outro, Doppelgänger. Ela também se faz presente na arte em geral e na literatura em particular, em especial a partir do século XIX, com o duplo representando o lado sombrio que habita em cada um de nós, os nossos desejos mais obscuros (vide, por exemplo, o clássico romance $O$ médico e o 
monstro - o estranho caso de Dr. Jekyll e Mr. Hyde, de Robert Louis Stevenson). Saltando para o século $\mathrm{XX}$, no livro $A$ metade sombria, que analisamos no presente ensaio, o escritor Stephen King retoma o duplo em sua mais pura essência, incluindo aquela da convivência tumultuada entre o ser original e sua duplicata, nos moldes do que fez Edgar Allan Poe no conto "William Wilson". O Doppelgänger, em King, começa com um "duplo" corriqueiro, o pseudônimo, mas logo envereda pelo insólito quando esse pseudônimo sai de uma tumba em que foi enterrado simbolicamente e ressurge como um ser à parte, cruel e que não hesita em matar quem se interpõe em seu caminho. Os crimes, é claro, são de início atribuídos ao personagem principal, Thad, que terá muito trabalho para provar que não foi ele e sim seu duplo, Stark, quem cometeu os assassinatos.

Palavras-chave: Duplo; Doppelgänger; A metade sombria; Stephen King.

Résumé: Depuis l'Antiquité, la figure du double est présent dans l'imaginaire humaine, sous ses formes et dénominations les plus variés - l'ombre, le reflet, le sosie, le frère jumeau, l'autre, le Doppelgänger. Elle est aussi présent dans l'art en général et dans la literature en particulier, en spécial à partir du $19^{\mathrm{e}}$ siècle, avec le double représentant le côté obscur que habite chacun de nous, nos désires les plus sobres (voir, par exemple, le classique roman L'étrange cas du docteur Jekyll et de M. Hyde, de Robert Louis Stevenson). En sautant dans le $20^{\mathrm{e}}$ siècle, dans le livre La part des tenèbres, que nous avons analysé dans cet essai, l'écrivain Stephen King reprend le double dans son essence la plus pure, y compris celle de la coexistense tumultuese entre l'être original et son duplicata, à l'instar de se qu'a fait Edgar Allan Poe dans la nouvelle "William Wilson". Le Doppelgänger, à King, commence par um "double" banal, le pseudonyme, mai passe vite à l'insolite quand ce 
pseudonyme émerge d'une tombe dans laquelle il a été symboliquement enterré et refait surface ent tant qu'être séparé et cruel, qui n'hésite pas à tuer quiconque se dresse sur son chemin. Les crimes, bien sûr, sont d'abord attribués au personnage principal, Thad, que aura beaucoup de travail pour prouver que ce n'est pas lui et si son double, Stark, qui a commis les meurtres.

Mot clés: Double; Doppelgänger; La part des tenèbres; Stepen King.

\section{INTRODUÇÃO}

A figura do duplo habita o imaginário humano desde a antiguidade, marcando presença também nas mais diversas manifestações artísticas. Seja por meio do sósia, do irmão gêmeo, da sombra ou do Doppelgänger propriamente dito, essa personagem ganhou especial destaque na literatura fantástica a partir do século XIX, com obras como o conto "William Wilson", publicado pelo escritor norte-americano Edgar Allan Poe em 1839, e o romance $O$ médico e o monstro - O estranho caso de Dr. Jekyll e Mr. Hyde, do escocês Robert Louis Stevenson, de 1886. Um século e meio depois do conto de Poe, a ideia do duplo pautou o livro objeto da presente análise, A metade sombria (no original, The dark half), que o norte-americano Stephen King lançou em 1989.

Em A metade sombria (publicado inicialmente no Brasil sob o título de $A$ metade negra) pode-se dizer que temos uma multiplicidade de duplos. Stephen King, o escritor real, criou Thaddeus "Thad" Beaumont, o escritor fictício e protagonista da trama, que é o primeiro Doppelgänger - até aqui, nada de sobrenatural. Thad, por sua vez, escreve sob o pseudônimo 
de George Stark, que se torna assim o duplo do duplo, mas continuamos ainda no terreno do natural, apesar de uma certa mudança de comportamento de Thad quando escreve sob seu nom de plume e que poderia ser creditada a maneirismos de artista. Por fim, não bastasse essa ficção dentro da ficção, Thad/ Stark criou o personagem Alexis Machine, que é quase um alter ego de Stark nas histórias que este escreve. Tudo vai bem até o dia em que Thad resolve acabar com seu pseudônimo e este se levanta do túmulo em que foi simbolicamente enterrado: é quando o insólito entra com força na história, e os crimes começam - assim como o terror vivido pelo protagonista da história e sua família.

Da mesma forma que o William Wilson, de Poe ou o Mr. Hyde, de Stevenson, Stark inferniza a vida de Thad: como o primeiro, tem algumas características semelhantes às do protagonista, com quem compartilha impressões digitais, e o persegue sem trégua; como o segundo, não tem escrúpulos em matar, deixando um rastro de corpos e de pistas que leva a polícia ao escritor (o escritor Thad, bem entendido). É uma revivescência do mito do lado sombrio (e criminoso) que habita em todos nós, e que, na trama, personificase no que poderíamos chamar de uma imagem invertida e corporificada do herói. Esse jogo de espelhos, em que o antirreflexo se confunde com o reflexo, colabora para criar uma dúvida naqueles que investigam os assassinatos cometidos por Stark, e também no leitor: haveria realmente duas pessoas, ou Thad e Stark seriam um só, apesar dele apresentar um álibi e negar ser o criminoso?

Neste ensaio, analisa-se como o escritor real, Stephen King, aproveita a figura do duplo - que, poderíamos dizer, é um elemento clássico do universo do insólito - para criar uma história envolvente 
e aterrorizante, no melhor estilo de Poe e Stevenson. E dele próprio também, claro, pois o insólito e o duplo são velhos conhecidos desse autor norte-americano.

Antes, porém, recordemos um pouco do que diferentes teóricos já disseram sobre a figura do Doppelgänger.

\section{SOMBRAS, IDENTIDADE, LOUCURA: O DUPLO NA TEORIA}

Segundo Berenice Sica Lamas, o duplo remete à noção de "igual/diferente", ligando-se a questões de identidade. De início, explica, esse mito tinha a ver com subjetividade, com interioridade projetada, e foi só mais tarde, a partir do século XVI, que "a noção do duplo sofre modificações e passa a representar a oposição dialética e o heterogêneo" (2011, p.31). Lamas salienta ainda que

no contexto da literatura fantástica, a questão do duplo emerge como personificação destes antagonismos humanos, trazendo a dualidade como uma impressão de estranheza entre os limites do real e do supra-real, do natural e do sobrenatural, do racional e do irracional, da vida e da morte, explicitando as contradições do homem e da sociedade. O duplo pode ainda representar a loucura em oposição à sanidade, ou os dualismos entre sentimento e razão, consciência e inconsciência, imanência e transcendência, e muitos outros. Enquanto desdobramento psíquico, o duplo traz uma inquietação interna: um outro eu, que aparece em forma desdobrada em outro tempo ou espaço. (2011, p.33)

Sigmund Freud já havia abordado o tema do inquietante em artigo de 1919, dizendo que este "sem dúvida, relaciona-se ao que é terrível, ao que desperta angústia e horror" (2010, p.329). 
Freud salienta, entretanto, que o inquietante não se confunde com o Unheimlich, ou seja, o não familiar, muito pelo contrário: "o inquietante é aquela espécie de coisa assustadora que remonta ao que é muito conhecido, ao bastante familiar" (2010, p.331) - isso aconteceria, por exemplo, pelo processo de negação ou repressão de algo, e, quando esse algo se mostra, inquieta, aterroriza. Assim é, podemos dizer, a figura do duplo: ele é um outro, mas é também alguém familiar, pois espelha o eu, estabelecendo com ele uma relação de identidade e, ao mesmo tempo, de diferença - a diferença é aquilo que se nega.

Esse estranho, que não é o Eu, pode ser encarado como aquilo que Ricardo Timm de Souza denomina "o Outro": "O Outro é fundamentalmente um estranho, um antirreflexo do Mesmo, a ruptura do jogo de espelhos autoiluminante ao qual se entrega o intelecto deixado só com suas representações" (2018, p.68). Esse outro, diz o estudioso, "rompe, assim, com seu aparecer, a estrutura de Totalidade na qual meu intelecto costuma autoentender-se e minha volição costuma agir" (2018, p.68).

Adotando a terminologia de Umberto Eco, podemos ainda ver o duplo como uma imagem refletida no espelho. Citando os escritos de Lacan, o teórico e escritor italiano afirma:

O espelho é um fenômeno-limiar, que demarca as fronteiras entre o imaginário e o simbólico. Entre os seis e os oito meses, a criança se defronta com a própria imagem refletida no espelho. Numa primeira fase, confunde a imagem com a realidade, numa segunda fase percebe tratar-se de uma imagem, numa terceira compreende que a imagem refletida é a sua. (1989, p.12) 
Clemént Rosset retoma e amplia a comparação, dizendo que, quando se trata do duplo, "a simetria é ela própria conforme a imagem do espelho: oferece não a coisa mas o seu outro, seu inverso, seu contrário, sua projeção segundo tal eixo ou tal plano" (2008, p.91). Para o estudioso francês, no que ele chama de "par maléfico que une o eu a um outro fantasmático" (definição na qual Stark, de $A$ metade sombria, se encaixa de forma perfeita), o eu não é necessariamente o real: "Não é o outro que me duplica, sou eu que sou o duplo do outro. Para ele o real, para mim a sombra. 'Eu' é 'um outro'; a 'verdadeira vida' está 'ausente'”' (2008, p.88-89).

Outra comparação do Doppelgänger é com a sombra, como lembra o psicanalista austríaco Otto Rank, um dos principais estudiosos do duplo e que é citado inclusive por Freud. Segundo ele, diversos povos temem a sombra - serem cobertos por ela, ou mesmo perdê-la -, o que seria uma das possíveis origens da figura. Além dessa "alma sombria", maléfica, o duplo, na sua leitura, presta-se a diversas analogias, tais como a paixão narcísica pela própria imagem, o mecanismo de defesa e a paranoia. Diz Rank: "O duplo, objetivamente, é o arquétipo de seu rival em tudo, mas principalmente na questão amorosa, e essa feição se deveria, em parte, à identificação com o irmão" (2013, p.126). O irmão, aliás, estaria na raiz do mito do duplo, embora não esgote sua compreensão, como bem ressalta Rank.

Independentemente da nomenclatura que se utilize, a questão da identidade, do igual e do diferente, permeia sempre as narrativas centradas no duplo. Conforme Ana Maria Lisboa de Mello,

o tema do duplo é motivo reincidente na literatura universal, dando corpo aos eternos conflitos 
humanos relativos ao dualismo bem/mal e razão/ instinto. [...] Através da noção do duplo, toda a problemática da identidade pessoal e das relações que se tem com as imagens parentais, bem como o eu profundo acham-se reunidos. É na alteridade, revelada em diferentes situações, que o eu descobre as faces inusitadas de si mesmo. [...]

O duplo funciona em relação ao eu como a consciência que aponta constantemente a dissonância entre os seus propósitos e as condições de existência, que prova, dia mais da, a inutilidade dos sonhos humanos. Por isso, o eu só nasce verdadeiramente no momento da morte física. (2002, p.184-185)

Em outro trabalho sobre o duplo, a mesma autora afirma que "cada ser humano seria o fruto da cisão no meio da união primitiva, estado de perfeição que foi perdido quando os homens ameaçaram os deuses" (MELLO, 2000, p.111). E o que acontece quando as duas partes cindidas se reencontram? A resposta está um pouco adiante no mesmo artigo, quando Mello diz que esse encontro "pode provocar angústia, mal-estar e medo, nem sempre passíveis de equacionar. Pode significar também o encontro necessário para solucionar a divisão interna e levar ao alcance da unidade" (2000, p.121-122). No caso concreto do romance de King, objeto do presente ensaio, tem-se a angústia, o mal-estar e o medo, embora não ocorra a unidade - ou seja, o equacionamento entre as duas metades não foi possível.

Voltando a Freud - para quem o duplo ou o sósia são "os mais notáveis entre os temas de efeito inquietante" (2010, p.350) -, este afirma que a projeção de uma espécie de consciência dissociada pode incorporar uma crítica do Eu: 
No Eu forma-se lentamente uma instância especial, que pode contrapor-se ao resto do Eu, que serve à auto-observação e à autocrítica, que faz o trabalho de censura psíquica [...]

Não apenas esse conteúdo repugnante para a crítica do Eu pode ser incorporado ao duplo, mas também todas as possibilidades não realizadas de configuração do destino, a que a fantasia ainda se apega, e todas as tendências do Eu que não puderam se impor devido a circunstâncias desfavoráveis, assim como todas as decisões volitivas coartadas, que suscitaram a ilusão do livre-arbítrio. (2010, p.352-353)

O pai da psicanálise destaca ainda outros dois pontos pertinentes para melhor compreendermos a fascinação e o temor que o Doppelgänger desperta e que o fazem ser figura constante na literatura. O primeiro é que além da aparência idêntica, o "original" e o duplo compartilham saberes, sentimentos e vivências (como ocorre, conforme veremos a seguir, na obra em análise); o segundo e que "o duplo tem seu sinal invertido: de garantia de sobrevivência passa a inquietante mensageiro da morte" (FREUD, 2010, p.352).

Um fator curioso é que alguns dos estudiosos citados veem o duplo também como a projeção da imagem do escritor na sua obra, aspecto que parece muito verdadeiro quando se percebe a recorrência de personagens escritores na obra de King (dos quais Thad e seu alter ego Stark são apenas o exemplo mais extremo e aterrorizante). Rank, por exemplo, cita a excentricidade de Poe, suas obsessões e até mesmo seus traços típicos de alcoólatra como indícios de que o personagem William Wilson o espelha (2013, p.67): “O conto 'William 
Wilson' é considerado por muitos como a autoconfissão de Poe, na qual ele descreve uma pessoa que, devido ao jogo e ao vício da bebida, decai cada vez mais para, por fim, destruir seu duplo bom". Já Rosset, analisando outro escritor - Guy de Maupassant e seu conto "O horla" -, repara também nesse fenômeno de que os personagens "não são sombras do escritor, mas o escritor real e verdadeiro, [que o autor] apenas imita de maneira lastimável: não é Ele que me imita, sou eu que imito Ele" (2008, p.89).

\section{BEM, MAL, DUALIDADE E DÚVIDA EM POE, STEVENSON E KING}

Como antecipado na introdução, King, em A metade sombria, insere-se numa tradição na qual foi precedido por nomes de peso como Poe e Stevenson. Não por acaso, o livro traz muitos elementos em comum com as obras já citadas desses autores, em especial com a do escocês. Um deles é a dualidade que se estabelece entre o bem e o mal, entre o lado (ou metade) bom e o lado (ou metade) mau das personagens; outro é a dúvida que se estabelece, em maior ou menor grau, sobre se existe mesmo um duplo, ou se tudo não passa da imaginação do narrador - vale lembrar que a hesitação é, segundo Tzvetan Todorov (2014), uma das características fundamentais do fantástico, em que as três obras podem ser enquadradas.

A medida da presença desses elementos e a forma como eles se apresentam variam de história para história. No conto "William Wilson", o narrador-protagonista de Poe fala do antigo colega de escola que, curiosamente, possuía o mesmo nome que ele e que o assombra no decorrer da vida, como se seguisse seus passos. Apesar disso, não chega a fazer a distinção entre o "eu-bom" e o "duplo-mau" - tanto que admite, já nos primeiros parágrafos do 
texto, que a virtude dele se desprendeu como uma capa e que desde pequeno tinha "tendências más" (1944, p.8). Mais adiante, confessa que os ataques entre ele e o colega eram recíprocos, além de falar da própria vida desregrada. Se a dualidade bem-mal não se faz tão forte, a dúvida sim: quando fala das semelhanças com seu duplo, por exemplo, o narrador declara que seus companheiros de classe, "graças talvez a alguma cegueira inexplicável, nem mesmo pareciam suspeitar" (1944, p.12) dessa igualdade. Seria cegueira, ou não existiria um segundo William Wilson?

Essa mesma dúvida de certa forma se estabelece para o leitor de $A$ metade sombria a partir do prólogo, em que um Thad préadolescente é operado e os médicos retiram, do seu cérebro, restos do que teria sido o feto de um irmão gêmeo. Daí a narrativa pula para o presente da trama, em que Thad é um escritor bemsucedido graças às histórias que escreveu sob o pseudônimo de Stark, uma espécie de "lado mau" que é irritadiço, bebe muito e não tem escrúpulos - uma personalidade bem diferente da dele próprio, mas na qual se "transforma" quando escreve. O escritor, entretanto, está cansado de se esconder sob aquele nome (além de estar prestes a ser desmascarado), por isso anuncia publicamente que está por trás de Stark e que, a partir de então, não haverá mais romances protagonizados pelo cruel Alexis Machine. Numa brincadeira para uma revista, Thad posa ao lado de uma lápide falsa com o nome Stark, na qual está escrito que ali jaz "um cara não muito legal".

Nesse ponto, é válido retomar 0 médico e o monstro. Também ali, o doutor Jekyll é o "cara legal" da história, que libera seu lado sombrio e não tão legal, Mr. Hyde (não à toa um trocadilho com 
a palavra inglesa hide, escondido), para poder cometer livremente seus pecadilhos e dar vazão a suas pulsões. Outra semelhança é que, tanto no romance de Stevenson quanto no de King, os duplos, quando corporificados - de propósito no primeiro caso, sem querer no segundo -, têm características físicas e comportamentos bem diferentes das dos seus "originais", na tal imagem invertida de que nos falou Rosset: enquanto Jekyll é alto e forte, Hyde é baixo e franzino; enquanto Thad tem cabelos pretos e constituição normal, Stark é loiro, de olho azuis e mais robusto - poder-se-ia dizer, a imagem invertida de que nos fala Rosset. Apesar disso, ambos os Doppelgänger mantêm certas peculiaridades daqueles a que espelham, como a letra idêntica, no caso de Hyde, e as mesmas impressões digitais, no de Stark.

Um outro fator de identificação/diferença, que aparece nas três histórias, é a voz. Em Poe, ficamos sabendo que a voz do "segundo" William Wilson era pouco mais alta que um sussurro (talvez para não ser possível perceber se era semelhante à do "original"). No clássico de Stevenson, assim como as aparências, as vozes das duas personalidades do personagem são diferentes - tanto que o mordomo Poole e o advogado Utterson, amigo do médico, têm certeza de quem lhes fala através da porta fechada do escritório não é Jekyll, e sim Hyde. Quando chegamos ao romance de King, a questão da voz reaparece: em princípio, ela é diferente, mas um exame mais sofisticado feito pela polícia aponta que a chamada impressão vocal (algo como a "impressão digital" da voz, em linguagem leiga) é a mesma.

De qualquer modo, lembremos que o duplo é a imagem invertida, segundo Rosset, ou, em outras palavras, a semelhança 
do duplo costuma ser apenas aparente, se levarmos em conta o que diz o pesquisador brasileiro Julio França. Para esse estudioso, por trás da similaridade estão "características que impedem a perfeita identificação entre duplicado e duplicata, e acaba gerando um conflito deflagrado por essas diferenças irreconciliáveis" (2009, p.4). Em outras palavras, "a coexistência entre o ser e seu duplo não costuma ser pacífica" (2009, p.4). Se isso não é verdade para o doutor Jekyll e o senhor Hyde, que se complementam, é para os dois William Wilson, e muito mais ainda, como veremos em breve, para Thad e Stark.

\section{A METADE SOMBRIA}

Deixando um pouco de lado os clássicos da literatura fantástica e detendo-nos na obra mais contemporânea de Stephen King, podemos dizer que, além de sua óbvia queda pelo insólito (não à toa é conhecido como "Mestre do Terror"), ele também tem o duplo como uma constante - se não o duplo como tema em si, pelo menos o uso do escritor, duplo do autor, como personagem, na linha sugerida por Rank e Rosset. Numa releitura rápida, é possivel identificar quase duas dezenas de escritores fictícios saídos da mente de King, totalizando pelo menos dez romances e um número semelhante de contos em que as personagens têm a mesma profissão do autor. Não iremos nos estender sobre eles, pois não é o objetivo deste artigo, mas vale destacar o que ele próprio escreveu no livro de não ficção Sobre a escrita: $a$ arte em memórias, sobre como inconscientemente havia se refletido na personagem Jack Torrance, de $O$ iluminado: "Eu era, no fim das contas, o cara que tinha escrito $O$ iluminado sem nem mesmo 
perceber (pelo menos até aquela noite) que estava escrevendo sobre si mesmo" $(2015$, p.86).

O que torna $A$ metade sombria ainda mais instigante é o fato de, nesse livro, termos um duplo "real", que é ao mesmo tempo um ser à parte e o próprio alter ego do escritor-personagem: George Stark, que até então era para Thaddeus Beaumont apenas um pseudônimo e de repente ganha vida e passa a trucidar todos que têm algo a ver com a sua "morte". Mas, para melhor compreensão da questão, é preciso fazer antes um resumo mais completo do livro, uma vez que até aqui foram dadas apenas algumas pinceladas sobre a história.

A metade sombria nos apresenta Thad, um escritor e professor que, depois da recepção mediana a seus dois primeiros livros, passou por um bloqueio da escrita e, para tentar vencer esse bloqueio, começou a escrever romances de ação sob o pseudônimo de Stark. Esses livros alcançaram grande sucesso, mas, depois de alguns anos, alguém percebe que Stark não existe, chantageia Thad e este resolve revelar que era ele o autor e acabar com pseudônimo e personagem para voltar a escrever romances mais "sérios". Para isso, dá entrevista para uma revista e enterra simbolicamente seu pseudônimo, posando para fotos em um cemitério, ao lado de uma lápide de mentirinha. É nesse ponto que começa o primeiro capítulo, após um prólogo sobre a infância do personagem. E é aí, também, que começam os seus problemas. Pouco depois da publicação da reportagem em que aparece a foto, a polícia bate à porta de Thad: um homem foi brutalmente assassinado e as impressões digitais do escritor foram encontradas no carro da vítima. Mas Thad tem um álibi, e, 
quando outras mortes começam a ocorrer, ele aos poucos toma consciência de que seu pseudônimo saiu do papel para a vida real.

É a concretização daquilo que diz Souza: "Estabelece-se pela presença de Outro uma anarquia traumática, a indefinição de um início, um nascimento possível [...] Todos os espaços definidos estão subvertidos" (2018, p.69). No livro, Stark é esse Outro que subverte, que vira o mundo do protagonista de cabeça para baixo - embora, até pouco tempo antes, ele fosse não o Outro, mas o Mesmo. Porém, seria realmente um Outro? Afinal, quando escrevia sob o pseudônimo, todo o comportamento de Thad mudava: bebia muito, escrevia apenas a lápis e não na máquina, tinha um humor mais instável. A grande pergunta é como poderia ser apenas ele mesmo, uma vez que ambos são radicalmente opostos - Thad é um pacato professor, casado, pai de dois filhos gêmeos, enquanto Stark, segundo a falsa biografia inventada por seu criador, é um solitário ex presidiário; Thad é calmo e de bom trato, enquanto Stark é irritadiço e cruel; até mesmo no aspecto físico eles são diferentes, como dito anteriormente.

Por outro lado, por vezes o leitor compartilha a incredulidade da polícia frente às alegações de Thad sobre a existência de Stark. Afinal, na perseguição promovida pelo duplo, podemos reconhecer o "delírio persecutório" descrito por Rank, quando este diz que as representações literárias do duplo "confirmam a convicção freudiana da disposição narcísica à paranoia", acrescentando ainda que

o sintoma mais evidente desse estado psíquico parece ser um forte senso de culpa que obriga o herói a não assumir a responsabilidade de certos 
atos do seu ego, mas sim transferi-la a um outro Eu, um duplo [...] Essa personificação dissociada dos impulsos e inclinações tidos antes como reprováveis, [...] dessa maneira indireta podem ser satisfeitos irresponsavelmente. (2013, p.128)

No romance, um pormenor muito bem pensado, que surpreende o leitor e amplifica a dúvida, é a reação dos filhos gêmeos de Thad quando Stark chega na casa - num momento em que Thad não está, e aí lembramos de 0 médico e o monstro, em que Hyde só aparece quando Jekyll não está presente. As crianças, ainda bebês, sorriem felizes para Stark e brincam com ele como se o conhecessem, apesar de sua aparência grotesca e de sua voz aparentemente diferente. Estariam reconhecendo nele o pai, escondido sob aquele rosto horrendo? O leitor tem essa hesitação, e, pensamos, a própria mulher do protagonista talvez a tenha. Quando o escritor chega em casa, entretanto, essa possibilidade é desfeita, pois temos, a um só tempo, o original e sua duplicata. Isso, talvez mais do que os assassinatos cometidos pelo duplo, amplia o terror psicológico desencadeado por essa figura de pesadelo, uma vez que as explicações usuais não são suficientes.

Pode-se dizer que, nesse contexto, aplica-se de forma literal a afirmação de que "o Outro assombra o texto" (SOUZA, 2018, p.72). Isso porque essa espécie de assombração de algo que nunca chegou a existir - seria a encarnação do irmão não nascido, indo na linha de pensamento de que o irmão é a origem do duplo? - vai cercando Thad e sua família até encurralá-los, na esperança de que o escritor atenda a seu desejo: Stark quer ser "ressuscitado", ou seja, quer que Thad volte a escrever sob esse pseudônimo, retomando o personagem Alexis Machine - que, 
aliás, tem características muito semelhantes às de Stark (talvez porque Thad, ao escrever seu romances populares, pensasse nos dois como um só, sendo ambos "caras não muito legais"). Assim, Stark assume não só o aspecto físico de Machine como alguns dos seus maneirismos, como andar com uma navalha afiada que usa para matar quem se interpõe em seu caminho.

Mas por que Stark quer que Thad reassuma o pseudônimo? Por que não toma nas mãos as rédeas do próprio destino, agora que tem um corpo só seu? Talvez porque ocorre algo salientado por França, que é a questão da dependência que se estabelece entre o duplo e aquele de quem ele se origina. Diz o estudioso:

Por ter sua existência condicionada - isto é, só poder ser entendido enquanto uma extensão de um outro ser, sob pena de perder sua condição de duplo - o duplo não abandona sua condição de simulacro, de mera sombra. Essa parece ser a peculiar condição ontológica do duplo: tem sua origem em um indivíduo, do qual pode se assemelhar até quase a identidade plena, mas não possui o mesmo estatuto dele: ele sequer é um "outro" pleno, uma vez que não tem valor em si mesmo, mas apenas aquele que o seu modelo Ihe fornece. (2009, p.3)

Resumindo, sem Thad, Stark não existe. Mesmo tendo, por algum fator não explicado, conquistado uma vida física em separado do seu eu original, o pseudônimo corporificado continua sendo um simulacro, uma sombra, uma metade que logo demonstra não ser inteira. Com o passar dos dias, seu corpo começa a se deteriorar, em especial o seu rosto, e ele percebe que, para se recuperar, precisará da ajuda de Thad. Mais exatamente, ele precisa que o 
escritor volte a escrever sob seu nome - até porque ele próprio já tentou escrever sozinho, mas não conseguiu.

Se Thad tem o poder de salvar Stark, poderíamos nos questionar, não teria também o poder de matá-lo? Retomando os teóricos da área, Rosset assim diz: "O pior erro, para quem é perseguido por aquele que julga ser o seu duplo, mas que é, na realidade, o original que ele próprio duplica, seria tentar matar o seu 'duplo'. Matando-o, matará ele próprio, ou melhor, aquele que desesperadamente tentava ser" (2008, p.89) - é o que acontece, por exemplo, em “William Wilson”, em que ao esfaquear sua duplicata o narrador percebe que matou a si mesmo. Rank também vê o assassinato do duplo como um suicídio disfarçado do herói, "sob a forma indolor de matar um outro Eu: uma ilusão inconsciente de separação de um Eu mau, punível" (2013, p.133).

Em A metade sombria, Thad vai dar-se em conta de que tem uma ligação forte com Stark, conseguindo inclusive invadir seus pensamentos sob certas circunstâncias, e que o que acontece com um, acontece com o outro, principalmente no que se refere à dor física (é muito bem concebida a "cena" em que ele fura a própria mão com um lápis). Por outro lado, ele sabe que, se fortalecer Stark, estará perdido. Sair desse dilema, e ainda provar à polícia que ele é inocente e Stark, o assassino, é o que Thad tentará fazer pelas quase cinco centenas de páginas da história.

O resultado é uma trama que ao mesmo tempo confirma, subverte e enriquece a extensa galeria dos duplos na literatura - pois, como bem diz Lamas, ele "suscita um sentimento de inexplicabilidade, inquietação e sobressalto em relação a esta ideia 
de igualdade e diferença ao mesmo tempo, a esta imbricação de unidade e diversidade" (2011, p.71).

\section{CONCLUSÃO}

Por tudo o que foi exposto, podemos dizer que o livro $A$ metade sombria se configura ao mesmo tempo numa narrativa de crime, suspense e terror, formada por uma espécie de jogo de espelhos com múltiplos duplos, o duplo "original" confundindose com outros duplos e reforçando, assim, o insólito. Esse efeito é intensificado pela utilização de diversos recursos metanarrativos, como a inserção, antes dos capítulos, de trechos supostamente retirados dos livros que Thad escrevia sob o pseudônimo de Stark - livros que não existem no "nosso" mundo real, uma vez que nem Thad nem Stark são reais, e sim apenas criações saídas da mente de King, o autor original e real. Nesses trechos se verifica a face cruel de Alexis Machine, a personagem criada por Stark/Thad, e que duplica Stark, como este duplica (de forma invertida) Thad, que por sua vez duplica o próprio King.

A própria naturalidade com que as personagens Thad e Liz (a esposa do escritor) aceitam a existência "real" do Outro - embora o policial encarregado da investigação dos crimes relute bastante em aceitá-la - colabora para estabelecer o pacto narrativo com o leitor. E para aqueles que ainda sentem um certo estranhamento com a situação, perguntando-se talvez quem imaginaria tal hipótese se a polícia batesse em nossa porta nos acusando de assassinato, é preciso levar em conta que escritor-personagem espelha King, e nada mais natural que o duplo do Mestre do Terror ter uma mente aberta ao sobrenatural e uma imaginação altamente 
desenvolvida. Além disso, como escreveu Freud há pouco mais de um século, "o efeito inquietante é fácil e frequentemente atingido quando a fronteira entre a fantasia e a realidade é apagada" (2010, p.364) - e essa fronteira, definitivamente, é ultrapassada em $A$ metade sombria.

A figura do irmão gêmeo, citada anteriormente, também tem importância na trama: embora Stark tenha saído da ficção para a "realidade", a mãe de Thad esteve grávida de gêmeos, mas aquele que seria o irmão do escritor foi absorvido por este ainda no útero materno, jamais nascendo (ao menos, no plano físico). Assim, acaba aparecendo na figura de Stark, a metade sombria de que fala o título e que é o outro lado do escritor pacato, pai de família e boa gente. Um lado ou metade que ele por muito tempo preferiu abafar - lembremos aqui a afirmação freudiana de que o duplo tem a ver com aquilo que é reprimido - e relegou para a ficção, mas que, por mecanismos que não vêm ao caso detalhar aqui, ganhou vida própria.

Também confirmando a teoria de Freud mencionada na segunda seção deste ensaio, de que o estranho assusta justamente por remeter ao que é conhecido, uma das coisas mais apavorantes do livro não é nem a sequência de mortes, nem a possibilidade de que Thad vá preso por crimes que seu alter ego cometeu, mas uma certa familiaridade que ele vê no assassino: afinal, por diversos anos, ele "foi" Stark, então sabe como este pensa e como ele age. O contrário também é verdadeiro, pois o duplo, por mais cruel que seja, sabe, quando necessário, usar de doçura, como quando brinca com os filhos de seu eu original (embora o faça para demonstrar o poder de vida e morte que tem sobre eles). Além disso, entre 
as vítimas de Stark estão desafetos do escritor, como aquele que tentou chantageá-lo, e isso, mesmo reforçando as suspeitas da polícia contra Thad, o faz de algum modo compreender um pouco os atos do outro.

Por fim, é válido destacar que King já teve o seu próprio "Stark", ou seja, assim como a personagem Thad, publicou algumas obras sob pseudônimo. Esse pseudônimo era Richard Bachman, e foi com ele que assinou A fúria, de 1977, A longa marcha, de 1979, A autoestrada, de 1981, O sobrevivente, de 1982, e A maldição do cigano, de 1984. Também como faz Thad em A metade sombria, King criou toda uma biografia para esse seu duplo, inclusive com a foto de um homem que supostamente seria Bachman acompanhando as edições. Cinco livros já haviam sido publicados como Bachman quando o pseudônimo foi descoberto, em 1985, por um livreiro que notou similaridades entre os estilos dos "dois" escritores.

Na época, King teria reagido à revelação com um relise (comunicado à imprensa) bem-humorado informando da "morte" de seu pseudônimo - qualquer similaridade com o que Thad Beaumont faz na ficção talvez não seja mera coincidência. No mesmo ano, os quatro primeiros livros assinados como Bachman foram reeditados num volume único, The Bachman books, que traz o nome dos dois "autores" na capa e incluiu ainda um ensaio intitulado "Why I was Bachman" ("Por que eu era Richard Bachman"). Nesse ensaio, entre outras coisas, King fala que há um certo estigma atual ligado à ideia de pseudônimo, e diz que o adotou para poder publicar mais obras num mesmo ano, uma vez que muitos editores não viam com bons olhos um mesmo autor publicar várias obras em curto período. É curioso que, apesar de o 
pseudônimo ter sido "morto" por seu criador, ele ainda assinaria dois livros posteriores, em 1996 e em 2006 - pelo menos o seu retorno foi tranquilo que o de Stark.

É possível, portanto, até pela proximidade das datas, que a descoberta de seu pseudônimo tenha influenciado King a escrever sobre o tema em A metade sombria. Entretanto, muitas questões que permeiam o livro e a construção desse duplo que ao mesmo tempo é o reflexo e o antirreflexo do autor já estavam presentes em obras anteriores, e continuaram presentes em obras que vieram depois, principalmente a questão do escritor-personagem - com muitos outros / duplos / reflexos, num jogo infinito de semelhanças e dessemelhanças - e a da fonte por vezes obscura da inspiração.

Para concluir, recorro outra vez às palavras do próprio King. Em seu site oficial, falando especificamente sobre o romance $A$ metade sombria, o escritor usa uma analogia com o "outro" quando explica que nesse livro ele tenta responder à pergunta frequente sobre de onde retira suas ideias: "Parece-me que para a maioria dos escritores há realmente outra pessoa escondida dentro, embora não seja sempre sombria" (grifo nosso). A partir disso, diz, pensou que seria "divertido escrever uma história sobre um romancista cuja musa foge do controle" - e essa musa, no caso, é o duplo. Também em Sobre a escrita, após já ter acusado certa semelhança com Jack Torrance, volta a se referir à identificação escritor-real e escritorpersonagem quando afirma ser justo perguntar se Paul Sheldon (outro escritor fictício saído de sua pena, dessa vez no romance Misery: Louca obsessão) é ele: "Certas partes dele são... mas acho que você vai descobrir, se continuar a escrever ficção, que todos os personagens têm um pouco do autor" (2015, p.164). 
Ou seja, quem escreve sempre está sujeito a ter duplos - e, também, a ser assombrado por eles.

\section{REFERÊNCIAS}

ECO, Umberto (1989). Sobre espelhos e outros ensaios. Rio de Janeiro: Nova Fronteira.

FRANÇA, Julio (2009). "O insólito e o duplo em William Wilson, de Edgar Allan Poe". Rio de Janeiro: UERJ. In https://sobreomedo.files.wordpress.com /2011/01/franc3a7a-julio-o-insc3b3lito-e-o-duplo-em-william-wilson-deedgar-allan-poe.pdf Acesso em 10.Mar.2020.

FREUD, Sigmund (2010). "O inquietante". In: . Obras completas. Vol.14, p.328-376. São Paulo: Companhia das Letras.

KING, Stephen (1989). "The Dark Half inspiration". The official web site. In https://stephenking.com/library/novel/dark_half_the_inspiration.html Acesso em 22.Jun.2019.

(1999). O iluminado. Rio de Janeiro: Objetiva.

(2012). The Bachman books. Londres, Hodder Paperbacks.

(2014). Misery: Louca obsessão. Rio de Janeiro: Suma de Letras.

(2015). Sobre a escrita: A arte em memórias. Rio de Janeiro: Suma de

Letras.

(2019). A metade sombria. Rio de Janeiro: Suma.

LAMAS, Berenice Sica (2011). O duplo: busca do si-mesmo. Porto Alegre: Evangraf.

MELLO, Ana Maria Lisboa de (2000). "As faces do duplo na literatura". In: INDURSKY, Freda; CAMPOS, Maria do Carmo. Discurso, memória, identidade. Porto Alegre: Sagra Luzzatto.

MELLO, Ana Maria Lisboa de (2002). Poesia e imaginário. Porto Alegre: Edipucrs. POE, Edgar Allan (1944). Poesia e prosa. Obras completas. Vol.2. Porto Alegre: Livraria do Globo.

RANK, Otto (2013). O duplo: um estudo psicanalítico. Porto Alegre: Dublinense. ROSSET, Clément (2008). O real e seu duplo. Rio de Janeiro: José Olympio. 
SOUZA, Ricardo Timm de (2018). Ética do escrever: Kafka, Derrida e a literatura como crítica da violência. Porto Alegre: Zouk.

STEVENSON, Robert Louis (1989). O médico e o monstro. O estranho caso do Dr. Jekyll e Mr. Hyde. São Paulo: FTD.

TODOROV, Tzvetan (2014). Introdução à literatura fantástica. São Paulo: Perspectiva. 